\title{
Bringing Others into Us: School Leadership Meeting the Politics of Identity
}

\author{
Jennie Billot, Unitec New Zealand, New Zealand
}

\begin{abstract}
How does a school maintain a sustainable identity within the rapidly changing society in which it is positioned? As a result of global migrations of people, the demographics of societies are changing and creating increasingly diverse communities, resulting in a challenging context for school leadership. The 'research territory' (Morrison, Lumby \& Sood, 2006, p. 281) of diversity has mainly been occupied by those outside the domains of educational management and leadership, so this paper aims to redress that imbalance. By examining the connections between diversity of population and school identity, I identify how inclusive practices aimed at social equity can be used to draw diverse groups into a larger unified school community. There has been much debate about what constitutes 'diversity' in general terms and, given the multiplicity of meanings for this concept, in this paper I focus on ethnocultural diversity which Au refers to as encompassing 'groups with shared histories and cultural knowledge' (1995, $p$. 85). I refer to research findings of an international study to identify strategies and practices developed and implemented by principals in New Zealand to address increasing ethnocultural diversity. Identity can be viewed as the 'combination of the internal experience of place and external participation in world and society' (Cockburn, 1983, p. 1). The principal holds a pivotal role in facilitating school identity and as leadership emerges from social constructions of the self, so the principal works recursively with the concept of identity in the agency of leadership. I identify the tension between efforts to value diversity and the achievement of social cohesion through consensus building and contend that espoused concentration on issues arising from the multi-dimensional nature of diversity can divert focus from the pursuit of equity.
\end{abstract}

Keywords: Ethnocultural Diversity, Identity, School Leadership

\section{Introduction}

$\mathrm{I}$ COMMENCE THIS paper by declaring my academic and political intent. I contend that educational communities cannot be examined in isolation in the same way that leadership cannot be circumscribed by just policy and social duty. Both entities exist within a quickly changing global environment where communities constantly refigure and priorities are modified. While this macro-dynamic influences political efforts to pursue social control, it may cause issues at the local level to be less visible. Local contexts may not always mirror global expressions, so by concentrating on the issues at large, we risk passing over what is happening locally. In the escalating call for educational researchers to acknowledge the impact of globalisation, tension has developed between finding global solutions and developing locally appropriate practices. In response to this tension and Dimmock's observation that 'astonishingly the leadership of multi-ethnic schools has received little attention in the literature' (2005, p. 82), I focus on the position of the school community within a changing global, national and local context.

Currently, migrations of large numbers of people are a global reality. These movements result from the desire to relocate in regions of greater opportunity through to forced migration arising from social or political dislocation. As a result, societies are changing and becoming more diverse in character (Dimmock, Shah \& Stevenson, 2004). Such changing demographics alter the nature of the environment in which individuals are situated, becoming apparent at the micro level of the community and school with school leadership roles becoming more pluralistic as schools face 'critical adaptive challenges' (Madsen $\&$ Mabokela, 2002, p. 1). In this paper I critique how school leaders create cohesive school communities within such complex circumstances. There has been concern raised that current research does not provide theory on how principals remain effective in changing environments. Acknowledging that there are a multitude of effects resulting from population change, I focus on issues related to the connections between diversity of population and school identity. Furthermore, I identify the legitimacy of how inclusive practices aimed at increasing equity can be used to draw diverse groups into a larger unified school community.

It is well documented that schools have been transformed by cultural multiplicity (Dimmock \& Walker, 2005), with the result that multiculturalism has become the dominant discourse of the current century, although as the term multiculturalism is applied in many different ways and to varied con-

THE INTERNATIONAL JOURNAL OF DIVERSITY IN ORGANISATIONS, COMMUNITIES AND NATIONS,

VOLUME 7, NUMBER 2, 2007

http://www.Diversity-Journal.com, ISSN 1447-9532

(C) Common Ground, Jennie Billot, All Rights Reserved, Permissions: cg-support@commongroundpublishing.com 
texts, it remains conceptually fluid. Debate regarding the nature of multiculturalism is outside the focus of this paper, but interpretations indicate that it includes more than multiple ethnicities and is more than the acceptance of diverse ethnicities. Consequently, this paper aims to provide further input into the discourse on diversity which has tended to remain outside the realm of educational leadership and management (Morrison, Lumby \& Sood, 2006).

It is within this complex milieu that I draw together the concepts of school leadership and school identity. I use examples of research findings from the New Zealand component of an ethnocultural trination study to identify dissonance between the efforts to value diversity, yet achieve social cohesion, in an effort to develop 'insight into ways in which leadership conceptualizes and operationalises contested concepts of inclusion and diversity' (Leo \& Barton, 2006, p. 168).

The New Zealand project was part of a qualitative exploratory study of ethnocultural diversity in 14 schools in the three cities of Calgary, Canada; Brisbane, Australia and Auckland, New Zealand (Billot, Goddard, \& Cranston, 2007). The aim was to uncover how principals identified and managed the issues associated with diverse student communities and the types of strategies used to enhance a school identity. While it is acknowledged that the research is limited by the fact that only principals' viewpoints have been sought, it is argued that the principal is certainly the first place to begin such research as he/she holds the ultimate accountability for the school (Billot, et al., 2007).

Five sample secondary schools were selected in Auckland on the basis of their diverse ethnocultural profiles and semi-structured in-depth interviews were held with the principals. The interviews were taped with the permission of participants and transcripts or summaries were made available to them for their approval. In this paper, I refer to several examples from the study that illustrate particular points that I make (pseudonyms are used when citing individual principals). A detailed account of the project, its design and findings, are the focus of a different paper (Billot, et al., 2007).

\section{Diverse School Communities}

Globalisation is causing changing demographic profiles in nations and local communities, resulting in the emergence of multi-cultural communities. As a result schools are becoming more diverse in nature. Dimmock and Walker (2005) talk about 'multi-ethnic' schools 'to describe a school whose student/staff profile has more than one race represented' (p. 9) and entails knowledge and responsiveness which come together to influence individual and group behaviour. As Au (1995) defines ethnicity as referring to 'groups with shared histories and cultural knowledge' (p. 85), it follows, then, that multi-ethnic schools are those containing varied and multiple groups of recognizably differing cultures.

Within the literature, the terms 'culture' and 'ethnicity' are sometimes used interchangeability, and there is significant contestation of the term 'culture' (Billot, 2005; Dimmock \& Walker, 2005; Featherstone, 1997). Given the multiplicity of meanings for diversity, I prefer to use the extended term of 'ethnocultural' to draw together both ethnicity and culture in a way that acknowledges the collective nature of language, ethnicity, culture and heritage among others (Goddard, 1997). Ethnocultural diversity is exemplified in schools by the 'social, cultural and linguistic heterogeneity of their students' (de Abreu \& Elbers, 2005, p. 3) which causes new challenges and demands new leadership practices and psychological tools (Holloway, 2003). Within the context of ethnoculturally diverse schools, principals find themselves negotiating the needs of many different groups, in a way that has 'absolute regard for the intrinsic worth of every individual' (Shields, 2006, p. 38).

As in many other western nations, New Zealand schools are currently experiencing changes to their student composition as different immigrant groups arrive and settle in the country. The total population of New Zealand stands at over 4 million, with $68 \%$ of the total being of European ethnicity, but its more recent and noteworthy feature has been a changing ethnic and cultural demographic. In particular, over $10 \%$ of the population identify with more than one ethnic group and numbers of people of Asian ethnicity have more than doubled since 1996 having increased by almost $50 \%$ since the 2001 census (Statistics New Zealand, 2006). There are also increasing numbers of immigrants from many other nations including the Middle East. This increasing immigration serves to diversify the population in what is a very small country.

The changing national demographic profile is reflected at the local level. As schools are managed within the policy of Tomorrow's Schools (Minister of Education, 1988) with the objective of locating the 'decision-making as close to the point of implementation' (Education Review Office, 1994, p. 5), principals seek to develop school communities that reflect and share the values and beliefs of the local community. This requires consistent reappraisal of the community characteristics. Hence the inter-relationships between the school and its local community are pivotal to acknowledging the values of all groups and the identity of individuals. 


\section{Diversity and Identity}

Creating a harmonious school community that has a sense of identity (Massey, 1991) becomes more challenging with increased student diversity. Its identity can be viewed as the 'combination of the internal experience of place and external participation in world and society' (Cockburn, 1983, p. 1). As a school's identity is created through interactions within several spheres of existence, including community and social and politico-environmental, it will reflect different cultural gender, ethnic and class influences. Strategies that work to enhance a cohesive community can operate at many levels and in different ways. Wardekker and Miedema (2001) claim that identity comprises a stable way in which individuals relate to themselves and others, but believe that it is more of a 'continuous activity of construction and deconstruction of developing, maintaining and evaluating personal commitments to values, persons and practices' (p. 37). In addition, they assert that as persons engage in many activities, their cultural framework remains dynamic and not always 'harmonic' (p. 37). If this is the case then it would seem that ways to develop a school identity would rely heavily on linking both individual and group identity, so that the school becomes a 'site of multiple but co-existing identities' (Pawson, 1996, p. 347).

The process for unifying a school community relies heavily on how the principal enacts their own values and beliefs and interfaces them with those of the school and local community. As the human identity is constructed through the development of the psyche and manipulated by the mores and values of the social environment, the school identity can be seen as the 'result of the organization of values transmitted through the social structure' (Billot, 1998 , p. 115). School identity consists of relational linkages situated in a particular location, for identification with a physical place can result from the 'desire for fixity and for security of identity in the middle of all the movement and change' (Massey, 1991, p. 26). Such is the significance of how students view their school; it can provide a locus for knowing one's place which has 'both spatial and political meaning' (Hayden, 1995, p. 16). Even if 'social discontinuities may disrupt a sense of knowing one's place', there is still scope for 'the extension of one's sense of place' (Billot, 1998, p. 113).

Creating a 'sense of identity' has aroused much debate in the literature (see for example Dei, 2005; Piper \& Garratt, 2004) for as the personal development of students cannot be seen as an 'extra' (Wardekker \& Miedema, 2001), the way in which group identity is constructed is important. The use of dichotomous constructs (Piper \& Garratt, 2004) such as insider and outsider, self and other, inhibit the 'rhizomatic' (p. 279), as in nomadic or fluid, development of identity, but such dichotomies often underpin strategies to develop cohesive communities. Efforts to assist assimilation and integration of immigrants, the acculturation of other ethnic groups and the aim to bring other ethnicities into a fuller appreciation of the customs and mores of the host group are all examples of well meaning intentions. These intentions are, however, based on the premise that the dominant group will determine the characteristics of the shared culture.

Individuals or groups may be perceived as different or 'other' when notions of identity are constructed by reflection of difference in comparison to oneself. Hence 'others' differ from those who develop inclusive practices, so efforts at inclusion run the risk of being used to seal the edges around the tensions of difference. Piper and Garratt (2004) believe that it is the 'relationship between differences rather than the differences themselves, which provides a basis for a more ethical style of teaching' (p. 288). It is through working in concert that allows for 'a politics of affinity based on shared purpose, rather than common identity (Larner, 1993, p. 99).

In an effort to develop initiatives that aim at equity for all groups, Wardekker and Miedema (2001) promote the strategy of equality, where cultural diversity is valued, as against the preclusion strategy in which examples of difference contrast with the 'we culture' and are viewed as an 'opposing they' culture (p. 41). As culture is viewed through a dominant knowledge base, so ethnocultural diversity will be framed through this lens and positively motivated attempts to create a unified community with a tangible identity can unintentionally create an 'other' by 'privileging commonality' (Piper \& Garratt, 2004, p. 283) over difference. Featherstone (1997) refers to how 'the established are able to develop a collective 'we-image' based upon a sense of superiority' (p. 124) and assume the role of integrating 'outsider groups.' If on the other hand diversity is valued rather than tolerated, or difference assimilated into the majority group, authenticity can be fostered in students so that they are true to their inner values.

It thus follows that initiatives to foster inclusivity in a school community may result in a fragmented sense of belonging and identity. On the other hand certain practices may enhance the school's perceived and experienced identity and in the process individual changes to identity provide chances for 'counterspaces' (Hayden, 1995, p. 19). Also, the sense of insecurity that can be felt with shifts in social identity can compensate for 'loss of place with the acquisition of identity' (Henley, 1992, p. 82). Effective community building rests with the principal and the way in which school practices work to achieve equity and social justice. Examples used by New Zealand prin- 
cipals indicate that there is no one formula for achieving such objectives, in fact it is imperative that contextually-driven strategies are developed.

\section{Questioning the Processes of Inclusion}

As 'identity is culturally constructed' (Billot, 1998, p. 236), the principal will develop mechanisms and practices that work to include all students. In many cases principals work through an agenda of inclusion which Shields (2006) believes can address the diversity of the school community in combination with participation and respect. This concept of inclusion is yet another highly contested term (Leo \& Barton, 2006) but it could be accepted that the moral value of inclusion is integral to ensuring equity at all levels. Critique of the inclusion strategy is based on the premise that by attributing certain forms of student identity through group processes, more fluid identities are less able to emerge and difference can be 'arrested' by 'rooting' cultural meanings (Piper \& Garratt, 2004, p. 285). In addition, ‘inclusion’ has been used as a 'rhetorical and political device to 'bind' or heal the tensions' between groups (Morrison, et al., 2006, p. 280-281).

Dei (2005) believes that difference is perceived as an 'exotic add-on to the European norm' or 'viewed as a problematic in which sameness and the stress on commonality is the preferred solution' ( $p$. 8). He suggests that singular solutions cannot be applied across diverse groups and questions the legitimacy of 'experts' and 'knowers' of the other (p. 11). The 'discourse of mosaic which cherishes difference and plurality and promotes an image of multiple, thriving, mutually respectful and appreciative of ethnocultural communities' is not enough (p. 11). He points to the need for continued political practice that seeks to challenge inequities through power sharing between groups.

Analysis of the transcript data from the New Zealand study provides some examples of group-based initiatives in the school context. One of the emerging themes from the interviews was the strong motivation of the principals to ensure inclusivity. One principal, Diana, summed this up in her explanation of her school's culture as having "an ethic of inclusion". Unlike the UK-driven national inclusion agenda (Dimmock, 2005), New Zealand education relies far more on individual principals responding proactively to their specific communities. The principals described a range of practices that sought inclusion, including an annual cultural week in which dance, food and performance are celebrated through to regular 'costume' days. Although some activities are common to all schools in the study (such as displaying flags from every nation represented in the school), each school has developed its own approach to creating a community that integrates its diverse student body. Murray believes that "there has to be coherence and a strong ethos that binds it together and it can happen, different kinds of glue can do that. I am always thinking about ... what are the neat things we can do to build the community, rather than thinking in terms of problems of groups. We celebrate difference but work as a family." This has resonance with Piper and Garratt (2004) who believe that 'celebration ensures that particular differences continue to matter' (p. 278).

Other initiatives include an induction process for international students so that "every single group in the school is enmeshed in the culture and made to feel part of things" (Murray). Another principal (Michael) has initiated a study in his school, specifically focusing on the issue of diversity in the multicultural school and recommending initiatives that are specific to the school in question, while George has intentionally appointed staff from the countries represented in his school. The most noticeable characteristic of the study schools was the diversity of approaches taken by the principals who worked as individual leaders within their own school context. This reflects the query made by Dimmock (2005) of the value of a 'one-size-fits-all' approach (p. 85) which may result in inequalities left unaltered and sometimes even compounded.

Despite the positive motivation for working to ensure inclusion, there is a risk of glossing over critical differences between and within diverse groups (Piper and Garratt, 2004). Fitzgerald (2006) has pointed to the danger of pursuing policies and practices that promote assimilation at the expense of diversity and difference. It may be that while principals are devising ways to enhance the school identity through inclusive practices, they need to ask themselves several pertinent questions. Have I really engaged with diversity? Are my initiatives to achieve inclusion often framed to be seen by others? Are my initiatives episodic rather than organisationally enmeshed?

Quick and Normore (2004) offer some recommendations for principals who are grappling with attaining a harmonious school community. They believe that the principal needs to blend the three ethics of leadership, namely 'critique (evaluating the current values, norms, beliefs and structures as well as the purpose of the school), justice (evaluating implicit and explicit practices that are unfair and unjust) and care (when practices focus on positive functioning based on collaboration and inclusive participation of all participants)' (p. 345). If these three components of leadership are combined, they assert that the principal will work towards a school world that reflects and 'exemplifies the very values he or she espouses' ( $p$. 346). 
I do acknowledge that the New Zealand principals in the study may not be representative of other schools, for they were selected as interviewees based on their leadership of noticeably diverse schools. However, from my general observation, schools in New Zealand highlight the many different ways in which schools approach their diversity, for some schools celebrate and incorporate their particular 'diversity' into their vision and philosophy, while others let it remain a school characteristic among many others. Recent interviews that I have held with Auckland secondary school principals have reinforced the view that schools that appear to have similarities, have many different characteristics and cultures and the resultant school culture is one that emerges from context-appropriate guidance and leadership.

\section{Conclusion}

In this paper I have sought to contribute to the 'research territory' (Lumby et al., 2004, p. 281) of diversity which has mainly been occupied by those outside the domains of educational management and leadership. Also, I have raised issues and questions that seek to address the deficiency in leadership theory that is still 'predicated upon solidarity through similarity and ignores diversity' (Lumby, 2006, p. 162). Blackmore (2006) extends this observation by suggesting that the discourse on diversity has been positioned within a market and managerialist context that tends to limit the 'promise of more inclusive and equitable schooling' (p. 182). While there are many forms of diversity, Haidt, Rosenberg and Hom (2003) claim that ethnic diversity, as a more recent global phenomenon, has a significant impact on school leadership, with school leadership roles becoming more pluralistic. As issues of diversity rise in the agendas of many disciplines, so it is timely that the discourse within educational leadership and management swivels towards the examination of leadership positioned within diverse social contexts.

Preliminary New Zealand findings from a research project indicate that principals are working in ethnoculturally diverse schools to develop stable and inclusive communities with which all students and staff identify and feel a sense of belonging. Varied practices and initiatives assist this objective but these should be contextually developed, as it is unlikely that a one-size-fits-all prescription can be found. Context should be seen as integral to any analysis of the complex lattice of issues that provide significant challenges for school principals.

As school identity is constructed through the integration of the values of both student and local communities, it is not axiomatic that what a school portrays as a harmonious identity, appears as such for the participants. How students give meaning to the school identity and how they construct their own place within that, will determine the degree of consistency between institutional and personal identity. The complexity of integrating representation and participation (Dimmock, 2005) may provide possibilities of a school reflecting the local community, but it also demands that strong links are made with the local community to assist in bridging the ethnocultural gap by ensuring that all voices are heard. Any work 'within' the school requires working 'beyond' the school (Dimmock, 2005, p. 91) which Bishop (2003) observes, can enhance a collectivist philosophy that embraces the wider community.

When interviewing the New Zealand principals I could not but be impressed by their commitment and the particularised decision-making that these individual school leaders demonstrated (Billot, 2005). This has resonance with the findings of a study of three New Zealand primary schools, in which school leaders worked passionately to develop a strong sense of community (Robertson \& Miller, 2007). However, I became aware of a tension between efforts to ensure inclusion of all, and initiatives that could appear as stand-alone activities that highlighted rather than celebrated difference. Parris (2005) indicates that identity emerges from and is 'grounded in concrete events, experiences and practices' (p. 52), so strategies that are developed need institutional consistency and strong alignment with the school philosophy for ethnocultural diversity. As certain episodic initiatives to be inclusive may accentuate difference and the 'other', it is important that such events are enmeshed into the organisational fabric and culture of the school. In particular, as Robertson and Miller (2007) noted in their recent study, schools that engender an 'inclusive philosophy of community' contribute in a number of ways to a 'more culturally inclusive society' (p. 101).

In light of the observation that school leaders are frequently driven by their own values and beliefs (Dimmock, 2005) there opens up a large area for future research, particularly in New Zealand where increasing diversity within the population is accelerating. In particular, how do principals recognise and articulate their own values and transpose them into motivational strategies that develop environments of equity and inclusion? Perhaps the challenge is to meet the multiplicity of difference rather than identifying that which is different and seeking to incorporate this 'other'. More positive efforts to enhance the linkages between groups rather than tolerating that which is different could provide a more valid approach to improve group interactions. Espoused concentration on issues arising from the multi-dimensional nature of diversity remains adrift from the emphasis on the pursuit of equity. 


\section{References}

$\mathrm{Au}$, K. H. (1995). Multicultural perspectives on literacy research. Journal of Reading Behaviour, 27(1), 85-100.

Billot, J. (1998). Women's agency in the North Shore and Waitakere cities of Auckland. Unpublished doctoral thesis: University of Auckland, Auckland, New Zealand.

Billot, J. (2005). Meeting the challenges of school diversity. Journal of the Secondary Principals Association of New Zealand (SPANZ), Aug/Sept, 9-14.

Billot, J., Goddard, J. T., \& Cranston, N. (2007). How principals manage ethnocultural diversity: Learnings from three countries. International Studies in Educational Administration, 35(2), 3-19.

Bishop, R. (2003). Changing power relations in education: Kaupapa Maori messages for 'Mainstream' education in Aoteoroa/New Zealand. Comparative Education, 39(2), 221-238.

Blackmore, J. (2006). Deconstructing diversity discourses in the field of educational management. Educational Management, Administration \& Leadership, 34(2), 181-200

Cockburn, C. (1983). Brothers: Male dominance and technological change. London: Pluto Press.

de Abreu, G., \& Elbers, E. (2005). The social mediation of learning in multiethnic schools: Introduction. European Journal of Psychology of Education, 20(1), 3-11.

Dei, G. (2005). Black education and the idea of African-centered/black-focused schools: equity and access in Canadian education. Presentation to the annual Meeting of the American Educational Research Association (AERA) 'Demography and Democracy in the Era of Accountability. Montreal, Canada.

Dimmock, C. (2005). The leadership of multi-ethnic schools: What we know and don't know about values-driven leadership. Education, Research and Perspectives, 32(2), 80-96.

Dimmock, C., Shah, S., \& Stevenson, H. (2004). Cultural diversity-identifying the implications for school leadership. Paper presented at the British Educational Leadership, Management and Administration Society (BELMAS) Research Conference: New Understandings in Educational Leadership and Management. July $9^{\text {th }}$, Oxford, UK.

Dimmock, C., \& Walker, A. (2005). Educational leadership: Culture and diversity. London: Sage.

Education Review Office. (1994). Effective Governance: School Boards of Trustees. National Education Evaluation Report, 7. Wellington: Education Review Office.

Featherstone, M. (1997). Undoing culture. Globalization, postmodernism and identity. London: Sage.

Fitzgerald, T. (2006). Walking between two worlds: Indigenous women and educational leadership. Educational Management Administration and Leadership, 34(2), 201-214.

Goddard, J. T. (1997). Monocultural teachers and ethnoculturally diverse students. Journal of Educational Administration and Foundations, 12(1), 30-45.

Haidt, J., Rosenberg, E., \& Hom, H. (2003). Differentiating diversities: Moral diversity is not like other kinds. Journal of Applied Social Psychology, 33(1), 1-36.

Hayden, D. (1995). The power of place. Urban landscapes as public history. Cambridge: MIT Press.

Henley, A. (1992). Space for herself. Frontiers, 13, 81-89.

Holloway, J. (2003). Managing culturally diverse classrooms. Educational Leadership, 61(1), 90-92.

Larner, W. (1996). Feminisation of the labour force. In R. Le Heron, and E. Pawson, (Eds.), Changing places. New Zealand in the nineties (pp. 97-101). Auckland NZ: Longman Paul.

Leo, E., \& Barton, L. (2006). Inclusion, diversity and leadership: Perspectives, possibilities and contradictions. Educational Management Administration and Leadership, 34(2), 167-180.

Lumby, J. (2006). Conceptualising diversity and leadership: Evidence from 10 cases. Educational Management Administration and Leadership, 34(2), 151-166.

Lumby, J., Morrison, M., Sood, K., Muijs, D., Harris, A., Briggs, B., et al. (2004). Leading for diversity: And now for something completely different? Presentation to the British Educational Leadership, Management and Administration Society (BELMAS) Research Conference: New Understandings in Educational Leadership and Management. July $9^{\text {th }}$, Oxford, UK.

Madsen, J., \& Mabokela, R. O. (2002). Introduction: leadership and diversity: Creating inclusive schools. Peabody Journal of Education, 77(1), 1-6.

Massey, D. (1991). A global sense of place. Marxism Today, 24-29.

Minister of Education. (1988). Tomorrow's Schools. Wellington: Government Printer.

Morrison, M., Lumby, J., \& Sood, K. (2006). Diversity and diversity management. Educational Management Administration and Leadership, 34(3), 277-295.

Parris, S. (2005). The geography of identity: The case of Canada's Chinatowns (1858-2002). International Studies in Educational Administration, 33(1), 52-61.

Pawson, E. (1996). Senses of place. In R. Le Heron, and E. Pawson, (Eds.), Changing places. New Zealand in the nineties (pp. 347-349). Auckland NZ: Longman Paul.

Piper, H., \& Garratt, D. (2004). Identity and citizenship: Some contradictions in practice. British Journal of Educational Studies, 52(3), 276-292.

Quick, P., \& Normore, A. (2004). Moral leadership in the 21st century: everyone is watching-especially the students. Educational Forum, 68(4), 336-347.

Robertson, J., \& Miller, T. (2007). School leadership and equity: The case of New Zealand. School Leadership and Management, 27(1). 91-103. 
Shields, C. (2006). Creating spaces for values-based conversations: The role of school leaders in the 21 st century. International Studies in Educational Administration, 34(2), 62-81.

Statistics New Zealand. (2006). 2006 Census of population and dwellings. Wellington: Statistics New Zealand. Retrieved 23/3/07 from www.stats.govt.nz .

Wardekker, W. L., \& Miedema, S. (2001). Denominational school identity and the formation of personal identity. Religious Education, 96(1), 36-48.

\section{About the Author}

Dr. Jennie Billot

$\mathrm{PhD}$ (Auck); BSc(Hons) (Lond); PGCertEd (Lough) Postgraduate Student Research Director: Unitec New Zealand. My research interests have emerged from working in different sectors of education. This includes teaching across primary, secondary and tertiary contexts, government initiated school review and research and directing a centre for educational research and Institutes for Educational Leadership (residential professional development programmes for school principals). I have also led internal, external (Ministry of Education) and international collaborative research projects, including projects focusing on teaching and learning. Following my commissioned research in the Pacific Islands, I was the invited facilitator of the Pacific Forum, initiated by the International Confederation of Principals in Sydney (2003) focusing on research into principalship in the Pacific. I currently co-ordinate and lecture in a course of Research Methods across disciplines and work through the Unitec Postgraduate Division to support postgraduate student research. My current research interests lie primarily in educational leadership, diversity and ethical leadership, the tertiary research culture and research preparation for tertiary students. 



\section{THE INTERNATIONAL JOURNAL OF DIVERSITY IN ORGANISATIONS, COMMUNITIES AND NATIONS}

\section{EDITORS}

Mary Kalantzis, University of Illinois, Urbana-Champaign, USA.

Paul James, RMIT University, Australia

\section{EDITORIAL ADVISORY BOARD}

Ien Ang, University of Western Sydney, Australia.

Samuel Aroni, University of California, Los Angeles, USA.

Duane Champagne, University of California, Los Angeles, USA.

Guosheng Y. Chen, RMIT University, Melbourne, Australia.

Jock Collins, University of Technology, Sydney, Australia.

Bill Cope, University of Illinois, Urbana-Champaign, USA.

Heather Marion D'Cruz, Deakin University, Geelong, Australia.

James Early, Smithsonian Institution, Washington, DC, USA.

Denise Egéa-Kuehne, Louisiana State University, Baton Rouge, USA.

Amareswar Galla, Australian National University, Canberra, Australia.

Barry Gills, University of Newcastle, UK.

Jackie Huggins, University of Queensland, Australia.

Andrew Jakubowicz, University of Technology, Sydney, Australia.

Ha Jingxiong, Central University of Nationalities, Beijing, China.

Peter McLaren, University of California, Los Angeles, USA.

Joe Melcher, Xavier University of Louisiana, New Orleans, USA.

Greg Meyjes, Solidaris Intercultural Services L.L.C, Falls Church, VA, USA.

Walter Mignolo, Duke University, USA.

Brendan O'Leary, University of Pennsylvania, USA.

Aihwa Ong, University of California, Berkeley, USA.

Peter Phipps, RMIT University, Melbourne, Australia.

Ronald Prins, Managing Director, Bos en Lommer Neighbourhood Council, The Netherlands.

Peter Sellars, Theatre, Opera and Film Director.

Michael Shapiro, University of Hawai'i, USA.

David S. Silverman, Valley City State University, North Dakota, USA.

Martijn F.E. Stegge, Diversity Platform, City of Amsterdam, The Netherlands.

Geoff Stokes, Institute for Citizenship and Globalisation, Deakin University, Melbourne, Australia.

Terry Threadgold, Cardiff University, Wales, UK.

Mililani Trask, Indigenous Expert to the Permanent Forum on Indigenous Issues for the Economic Council of the UN Assembly, Hawai'i, USA.

Marij Urlings, Dean, School of Health Inholland University, Amsterdam-Diemen, The Netherlands.

Joanna van Antwerpen, Director, Research and Statistics, City of Amsterdam, The Netherlands.

Grethe van Geffen, Seba Cultuurmanagement, Amsterdam, The Netherlands.

Rob Walker, Keele University, UK.

Ning Wang, Tsinghua University, Beijing, China.

Owens Wiwa, African Environmental and Human Development Agency, Toronto, Canada.

Please visit the Journal website at http://www.Diversity-Journal.com for further information:

- $\quad$ ABOUT the Journal including Scope and Concerns, Editors, Advisory Board, Associate Editors and Journal Profile

- $\quad$ For Authors including Publishing Policy, Submission Guidelines, Peer Review Process and Publishing Agreement

SUBSCRIPTIONS

The Journal offers individual and institutional subscriptions. For further information please visit http://ijd.cgpublisher.com/subscriptions.html. Inquiries can be directed to subscriptions@,commongroundpublishing.com

INQUIRIES

Email: cg-support@commongroundpublishing.com 